\title{
Emerging Technologies, Market Segments, and MarkeTrak 10 Insights in Hearing Health Technology
}

Brent Edwards, Ph.D. ${ }^{1}$

Hearing health care is rapidly changing through innovation in technology, services, business models, and product categories. The introduction of hearables and over-the-counter (OTC) hearing aids in particular will change the market for hearing help and the role of the hearing care professionals (HCPs). This article focuses on how these products will be differentiated from $\mathrm{HCP}$-fit hearing aids through their ability to address the unmet needs of different consumer segments within the population of people with hearing dysfunction. The unmet hearing needs of each segment are discussed, and the size of each segment estimated, demonstrating a large potential market for hearables and a smaller potential market for hearing aids than has been previously mentioned in the literature. The results from MarkeTrak 10's survey of consumers' attitudes toward an OTC model are reviewed, showing that approximately half of both hearing aid owners and nonowners are uncomfortable doing hearing- and hearing aid-related tasks on their own without the assistance of an $\mathrm{HCP}$ and would be unlikely to purchase OTC hearing aids if available today. MarkeTrak data are also shown that demonstrate that the majority of hearing aid and personal sound amplification product owners believe that the HCP helped or would have helped with their hearing devices. Finally, challenges to OTC hearing aids becoming successful are discussed.

KEYWORDS: hearing aids, over the counter, hearables, hearing loss

${ }^{1}$ National Acoustic Laboratories, Sydney Australia.

Address for correspondence: Brent Edwards, Ph.D., National Acoustic Laboratories, Level 4, 16 University Avenue, Macquarie University, NSW 2109, Australia (e-mail: brent.edwards@nal.gov.au).

MarkeTrak 10: Patients; Providers; Products; and Possibilities; Guest Editor, Thomas A. Powers, Ph.D.
Semin Hear 2020;41:37-54. Copyright (C) 2020 by Thieme Medical Publishers, Inc., 333 Seventh Avenue, New York, NY 10001, USA. Tel: +1(212) 760-0888.

DOI: https://doi.org/10.1055/s-0040-1701244.

ISSN 0734-0451. 


\section{INNOVATION IN HEARING AIDS}

Innovation is anything that creates value in new ways. This is typically embodied in the creation of a new product, service, process, or business model that addresses unmet needs of a person or organization. ${ }^{1}$ By this definition, innovation has had a significant impact on hearing health care over the past two decades and is continuing to change the hearing health care landscape.

This changing hearing health care landscape has been followed over the past 30 years through the MarkeTrak series of surveys. The MarkeTrak research has documented much of the changes in terms of the market penetration, consumer views on technology, satisfaction with professional services, and the core technology of hearing instruments. The latest survey, MarkeTrak 10, has provided additional insights in these topics and will be explored as we examine the innovation and trends in the hearing health care space.

Much of the hearing health innovation over the past two decades has been in the form of technology. Two technology platforms in particular transformed the hearing aid technological landscape by enabling a series of innovations that met the unmet needs of those with hearing loss and hearing care providers ( $\mathrm{HCPs}$ ). The introduction of digital signal processing (DSP) in a hearing aid in 1996 and of programmable DSP in 1999 allowed for the rapid development and implementation of sophisticated signal processing features such as feedback cancellation, noise reduction, frequency lowering, data logging, and others. These innovations improved the audibility, sound quality, speech understanding, and usability of hearing aids when fit and adjusted properly, with secondary benefits such as reduced cognitive load, ${ }^{2,3}$ mental fatigue, ${ }^{4}$ and reduced social isolation. ${ }^{5}$ In 2004 , the introduction of wireless technology led to the development of innovative features such as streaming sound between hearing aids and consumer electronics products, connectivity between hearing aids and smartphones that enabled apps to give greater hearing aid control to the user, and data sharing between left- and right-worn hearing aids that enabled beamforming and other sophisticated signal processing benefits for hearing aid wearers. 6,7
In recent years, innovation has expanded beyond technology into services, business models, and product categories for new market segments.

Teleaudiology, or more broadly "connected hearing health," is allowing HCPs to provide hearing health services to their clients remotely. Innovation in this area has allowed for the provision of traditional audiological services to a patient in a remote location, improving accessibility to hearing health services. ${ }^{8}$ Connected hearing health is also improving the connection between patient and HCP by allowing the HCP to provide follow-up services like counseling and hearing aid fine-tuning remotely, eliminating the need for an office visit while also giving the opportunity for faster and more frequent service delivery. ${ }^{9}$

Innovation in hearing aid distribution models is disrupting the traditional way one gets a hearing aid, which historically has been to visit an HCP's office to have one's hearing loss measured and be fit with a hearing aid. While mail order hearing aids and online hearing tests have existed for well over a decade, ${ }^{10}$ some of those were distributed in violation of Food and Drug Administration (FDA) and state regulations. A new generation of hearing aids is now being distributed that meet FDA and state regulations, involving audiologists in the delivery process via online or telephone communication, following Good Manufacturing Practices, producing proper labeling on the products, and following other medical device regulations for hearing aids. Hybrid approaches to hearing aid distribution also are emerging, where audiologist services are provided online or by phone and the hearing aid is mailed to the user with instructions for self-fitting, while still allowing for the possibility of an in-person visit to an HCP's office and face-to-face professional assistance. ${ }^{11}$ People can even test their hearing on their own with an FDA-approved hearing screening system, ${ }^{12}$ and smartphone apps can do a reasonable job at measuring pure-tone thresholds in a quiet environment. $^{13}$

Innovation in new product categories is helping to develop new market segments. Hearables, or ear-level worn earpieces with wireless connectivity, ${ }^{14}$ have been developed that are multifunctional, providing wireless audio 
connections to devices like smartphones and remote microphones, sensors that measure biological function, microphones that enhance and augment environmental sounds, and more. Hearables are not medical devices regulated by the FDA because they are not intended for use in the treatment of hearing loss, and as such their distributors and manufacturers do not have to follow the requirements that those for hearing aids do. As technology typically associated with hearing aids, such as directional microphones or noise reduction, starts to appear in hearable devices, whether a device is a hearing aid or a hearable will become more difficult to determine. Ultimately, the same physical device could be either a hearing aid or a hearable and which one it is will depend only on its intended use, that is, whether it is intended to treat hearing loss or not.

We are likely to see a continuation of service and business model innovations that develop new hearing market segments with the coming creation of an over-the-counter (OTC) hearing aid category by the FDA. These OTC hearing aids may expand the reach of hearing health care by meeting the unmet needs of a segment of people with hearing loss who, until now, have rejected traditional hearing aids as a solution.

\section{OVER-THE-COUNTER HEARING AID LEGISLATION}

Two reports were influential in promoting the creation of an OTC category of hearing aidsthe President's Counsel of Advisors on Science and Technology (PCAST) report ${ }^{15}$ and the National Academy of Sciences, Engineering and Medicine (NAS) report. ${ }^{16}$ Both of these reports noted that affordability and accessibility were significant barriers to some people getting hearing aids. As a response, the Over-theCounter Hearing Aid Act of 2017 mandated that the FDA create an OTC category for hearing aids that is intended for adults with mild-moderate losses whereby the OTC hearing aids could be acquired without the involvement of a licensed professional, as mandated by many state regulations. ${ }^{17}$ These OTC hearing aids could be sold in stores, by mail, online, or any other direct-to-consumer distribution channel.
Hearing aids have been sold for many years through the Internet and other channels without the involvement of licensed professionals in contrast to claims of poor accessibility and affordability of hearing aids. (At the time of this writing, a search on Amazon and Google for "cheap hearing aid" produces a list of many hearing aids that can be bought online for around $\$ 100$ or less.) Regardless, the OTC hearing aid law will allow organizations to legally sell hearing aids directly to consumers that it might not have otherwise, as long as those organizations abide by the regulations set by the FDA. The benefit to the consumer will be knowing that those hearing aids have met FDA medical device requirements such as being manufactured under a proper quality management system, will have appropriate labeling on the products, and meet other requirements without being in violation of state regulations requiring the involvement of certified professionals.

The OTC Hearing Aid Act of 2017 requires the FDA to create an OTC hearing aid category and issue regulations on them by August 2020.

\section{MARKET SEGMENTATION}

With these emerging new categories of hearing devices that could potentially have similar, if not identical, features, the question arises of how to differentiate between hearables, HCPfit hearing aids, and OTC hearing aids. One way to determine the differences between these products is to consider for which population groups these solutions provide value.

Innovations find success by providing solutions for the unmet needs of a group of customers. So, if hearables and OTC hearing aids are to be successful, what unmet needs will they meet and whose needs will those be? Consider the total population of people with some sort of auditory dysfunction, whether due to audiometric hearing loss, central auditory nervous system issues, or other deficits. ${ }^{18} \mathrm{~A}$ reasonable premise is that this population has unique hearing needs that could be helped by those innovative solutions.

This population of people with auditory dysfunction can be segmented into distinct groups of people with different characteristics and potentially different hearing needs. Fig. 1 


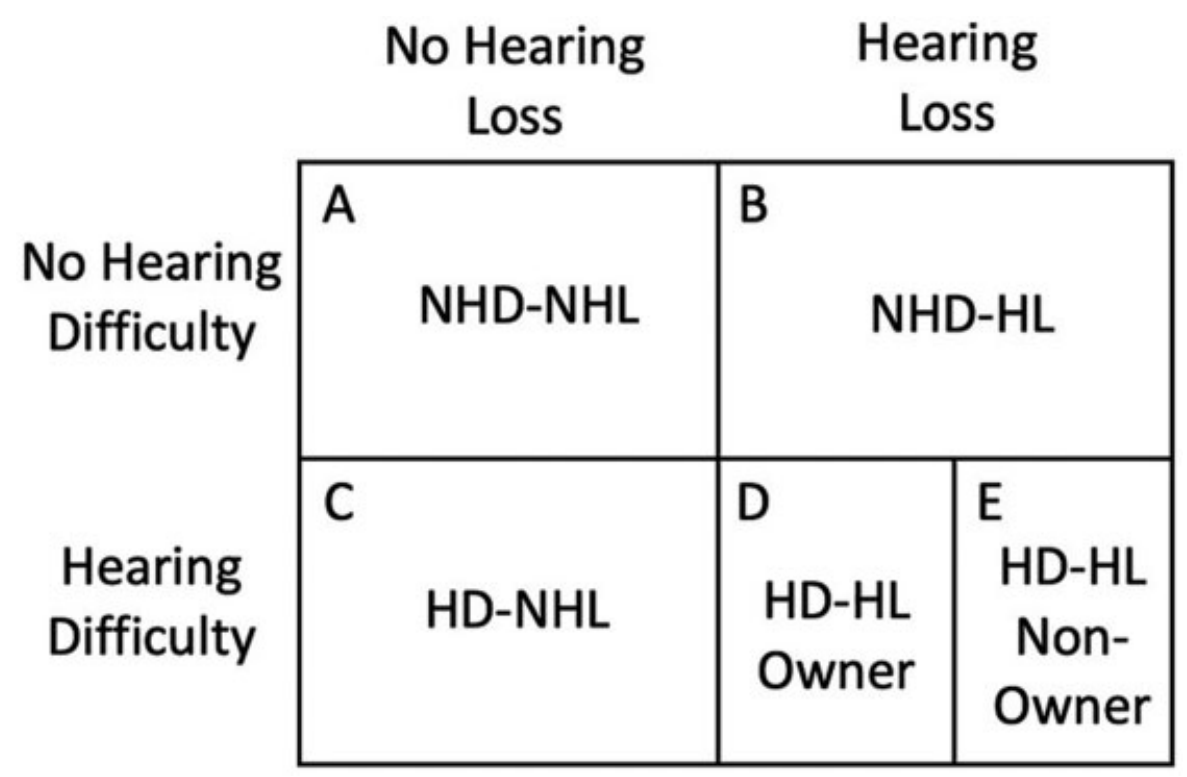

Figure 1 The total population with hearing dysfunction segmented according to whether they self-report as having hearing difficulty or not (HD or NHD, respectively) and whether they have an audiometric hearing loss or not (HL or $\mathrm{NHL}$, respectively). Those with both self-reported hearing difficulty and an audiometric hearing loss (HD-HL) are further segmented into hearing aid owners and hearing aid nonowners.

shows one possible segmentation for this population. Each segment is characterized by whether someone self-identifies as having hearing difficulty (HD) or not (NHD), and whether someone has an audiometric hearing loss (HL) or not (NHL). Of the HD-HL group-those who self-identify as having hearing difficulty and who also have an audiometric hearing loss - a further segmentation can be made on whether they have accepted HCP-fit hearing aids as a solution for their needs or not. Thus, the population of people with hearing dysfunction can be segmented into five distinct groups, each with the possibility for unique hearing needs that may be met by different hearing solutions.

\section{No Hearing Difficulty Group}

Segments A and B in Fig. 1, the NHD-NHL and NHD-HL groups, respectively, represent those with some form of auditory dysfunction but who do not self-identify as having hearing difficulty. In other words, for whatever reason they do not have a normal auditory system, but they do not perceive themselves as having a hearing problem.
Segment A, the NHD-NHL group, will not be considered candidates for any hearing solutions primarily because they do not perceive themselves as having any hearing difficulty and therefore do not perceive themselves as having any unmet hearing needs, nor would an audiogram identify them as having a hearing loss; so, no HCP would recommend any solutions if the person happened to have their hearing tested.

Segment B, the NHD-HL group, is particularly interesting because they do have a measurable hearing loss yet do not self-identity as having hearing difficulty. Reasons for their lack of self-perceived hearing difficulty could be because they have a lifestyle that does not require listening in difficult situations and therefore they have not experienced any hearing difficulty, they are successfully compensating for loss of audibility through extra cognitive effort, or they lack general self-awareness of their situation or condition. ${ }^{19-21}$ (This group does not include those who are personally aware but will not admit they have hearing difficulty to others.) Regardless of why, they do not believe that they have hearing difficulty and are likely unaware that they have an audiometric hearing loss. This group might benefit from 
wearing a hearing aid that improves audibility, but they are unlikely to ever realize that benefit because they do not believe that they have a need for improved hearing and will not seek out hearing solutions. If they happened to have their hearing tested such as at a screening event, they will be unlikely to follow through with a visit to an $\mathrm{HCP}$ given their lack of a perceived need. Therefore, issues such as accessibility, affordability, or stigma are not reasons that this population does not wear hearing aids. They simply would not present to an HCP or seek hearing help of any kind because they do not have a need for hearing help.

When considering the viable market for hearing aids or hearing help, neither the NHD-NHL group nor the NHD-HL group should be included. More specifically, estimates of how many people who need hearing aids but do not have them should not include the NHDHL population even though they have a measurable hearing loss. ${ }^{22}$ The populations in Segments $A$ and $B$, however, are potential customers for consumer audio products such as headphones, earphones, or other audio devices that address other hearing needs such as access to music, podcasts, augmented audio, and other offerings that are marketed to people with normal hearing.

\section{Hearing Difficulty, No Hearing Loss Group}

Segment C in Fig. 1 is the HD-NHL group. These are people who self-identify as having hearing difficulty but have audiometrically normal hearing. Many people within this population present at audiology clinics but are offered no help because they are not diagnosed with a hearing loss. Hearing aids, whose primary function is to improve audibility through the provision of gain, are presumed not to be a solution for this population since audibility as measured by the audiogram is not compromised. People in this segment may have a variety of reasons why they have difficulty hearing, including auditory processing disorder, cognitive dysfunction, attention-deficit disorder, and synaptopathy. ${ }^{23,24}$ This population could benefit from technology that helps with their self-reported hearing difficulty but are presumably seeking something other than amplification since audibility is not an issue. Their needs are primarily with speech understanding and they may benefit from devices that improve the speech-to-noise ratio or provide some other mechanism for improving the understanding of their speech target, whether it is the speech of someone in person, on a television, or on a phone. Thus, persons in the HD-NHL segment are potential candidates for hearables, which are not intended to compensate for hearing loss but to improve hearing ability in some way other than the provision of amplification. Whether any specific person in this group is a candidate for any specific hearable device will depend on whether that device has capabilities to meet the individual needs of the person.

The HD-NHL population should not be considered part of the viable market for hearing aids, whether OTC or HCP delivered, because they are considered to have normal audibility that is assumed to be a prerequisite for needing the amplification of a hearing aid.

\section{Hearing Difficulty, Hearing Loss Group}

Segments D and E make up the HD-HL group-those who self-identity as having hearing difficulty and also have audiometric hearing loss. This group is the target market for hearing aids because they have audibility issues that could benefit from gain and they have a selfrecognized need.

The HD-HL group in Segment D consists of traditional hearing aid wearers, meaning that they had their hearing tested by an HCP and were fit with hearing aids. While they may have delayed obtaining hearing aids once they realized that they had a need, they did not reject the traditional approach to obtaining hearing help from an HCP and a hearing aid.

The HD-HL group in Segment E, however, have not pursued hearing aids through an HCP even though they have an audiometric loss and self-identify as having a need to hear better. There are many reasons that someone would have treatable hearing loss and know that they have hearing difficulty yet still not pursue a solution. The PCAST and NAS reports suggest that accessibility and affordability are two of the main reasons. Additional reasons include stigma effects, lack of awareness of how to take action, lack of belief that hearing aids can be beneficial, 
and lack of support from significant others. ${ }^{25-28}$ Their needs are not unmet for lack of a technology solution but for lack of a solution that helps them make a decision to get a hearing aid by meeting such unique needs as affordability, accessibility, confidence in treatment success, or eliminating stigma. For those in this segment who have not obtained a hearing aid from an HCP because of affordability and accessibility, OTC hearing aids are attractive as a hearing health solution. OTC hearing aids will not de facto address any of the other reasons that cause people in this group to not get a hearing aid through an HCP, although positive brand recognition and effective direct-to-consumer marketing could address such issues as lack of a belief of benefit from hearing aids or lack of support from significant others.

Thus, each segment has different hearing help needs that could be addressed by different hearing device solutions. Knowing this would help estimate the size of the market for each solution: hearables, HCP-fit hearing aids, and OTC hearing aids.

\section{POPULATION SEGMENT ESTIMATES}

While there has been no attempt to estimate the population size within each segment within Fig. 1 with a consistent criterion for each, there have been independent attempts to estimate the population size of individual segments or the sum of a subset of the segments. For example, the prevalence of hearing loss in adults has been estimated from both self-reported data and from audiometric hearing loss data, that is, either estimates of the sum of Segments C, D, and E or the sum of segments B, D, and E, respectively. Combining these estimates with estimates of individual segments, one can use simple arithmetic to estimate the population size of segments for which there are no data. While the criteria with which people are associated with each segment for the purpose of estimating population size are not consistent (e.g., criteria for no hearing loss, criteria for self-identifying as having hearing difficulty, or age criteria considered for the estimates), we can still attempt to estimate the size of each segment from various sources.
Several estimates exist for the size of the total adult population who self-report as having hearing difficulty (i.e., the sum of Segments C, $\mathrm{D}$, and $\mathrm{E}$ or the sum of the HD-NHL and the HD-HL populations). MarkeTrak 10 has found that $10.8 \%$ of all respondents $(n=55,650)$, with $13.1 \%$ of adults, self-report as having hearing difficulty, which is 32.6 million people based on a total U.S. adult population of 249.2 million in $2018 .^{29}$ Blackwell et al ${ }^{30}$ estimated the percentage of adults who had hearing difficulty to be $15 \%$, which is 37.4 million. A challenge with each of the different population estimates is the criteria used. They rely on self-reported data but used different questions on which to make the determination that someone perceives themselves to have hearing difficulty.

Similarly, several estimates have been made on the population size of adults with audiometric hearing loss (the sum of Segments B, D, and E). Goman and $\mathrm{Lin}^{31}$ recently estimated the number of people in the United States aged 20 and over with audiometric hearing loss to be 38.1 million. We can safely assume that the number of people aged 18 and older also to be 38.1 million as well since the number of people aged 12 to 19 with hearing loss is only 0.06 million. ${ }^{31}$ With a total adult population size of 249.2 million and a total adult HL population size of 38.1 million, the total NHL population size must be the difference or 211.1 million.

Several estimates exist for the size of the population of people with normal audiometric hearing but self-reported hearing difficulty (Segment C), varying from $20 \%$ of the NHL population $^{32}$ or 42.2 million people, to $29 \%$ of the NHL population ${ }^{33}$ or 61.2 million people, to a range of 20 to $40 \%$ of the NHL population ${ }^{34}$ or 42.2 to 84.4 million people. Tremblay et $\mathrm{al}^{35}$ using a much stricter criteria for normal audiometric hearing of pure-tone thresholds less than $20 \mathrm{~dB} H \mathrm{HL}$ at $0.5,1,2,3,4,6$, and $8 \mathrm{kHz}$, found that $12 \%$ of a cross-section population of the Beaver Dam Offspring Study had self-reported hearing difficulty, which would be 25.3 million out of the 211.1 million NHL adults referenced earlier. These different HD-NHL population size estimates vary in large part due to the differences in criteria used to classify someone as having no audiometric hearing loss and having self-reported hearing difficulty. Note also that 
these estimates for the size of Segment $\mathrm{C}$ exceed the aforementioned estimates for the size of the sum of Segments C, D, and E, which is mathematically inconsistent. Again, the challenge in comparing these population estimates is the lack of consistency in criteria. In order for the estimate of the HD-NHL (Segment C) population size to be reasonably smaller than the estimate of the total HD (the sum of segments C, D, and E) population size, we will use the smaller population estimate of 25.3 million from Tremblay et al for the HD-NHL group and the larger population estimate of 37.4 million from Blackwell et al for the HD group.

There have been many attempts to estimate the population size of HD-HL adults who wear hearing aids, Segment D. Chien and $\mathrm{Lin}^{36}$ estimated the number of people over 50 who have hearing aids to be 3.8 million based on NHANES data, which is an incomplete estimate of the total adult population who wears hearing aids in the United States since it does not include people younger than 50 years. Popelka et $\mathrm{al}^{37}$ estimated the percentage of people with hearing loss in their worst ear who have hearing aids to be $14.6 \%$. Applying this percentage to the Goman and Lin's estimate of 60.1 million people with audiometric loss in at least one ear ${ }^{31}$ gives an estimate of 8.8 million people with hearing aids, although Popelka et al's estimate is for the total population, not just adults. MarkeTrak 10 estimates that $3.7 \%$ of the total population have a hearing aid, resulting in an estimate of 12 million people. Again, this number is for the total population, not just adults. MarkeTrak 9 estimated that less than $1 \%$ of the population younger than 18 years had a hearing aid which is 0.7 million people, which would put the total adults with hearing aids at over 11.3 million people.

We can cross-check these hearing aid owner numbers with the number of hearing aids sold in a year. Given that an average duration someone keeps a hearing aid before replacing it with a new one is approximately 5 years, one could estimate the population size of hearing aid wearers by summing the number of hearing aids sold over the past 5 years. This totals 17.9 million devices. $^{38-42}$ Over $90 \%$ of people fit with hearing aids are fit with two devices, ${ }^{43}$ which means that 17.9 million hearing aids were fit on at least 9.4 million people over the past 5 years. If we subtract the estimate of 0.7 million people under 18 who have hearing aids from this number, the estimate for adults with hearing aids becomes 8.7 million, which is remarkably close to the 8.8 million derived from the data of Popelka et al and Gorman and Lin. This number, of course, is not exact because there were some people who bought their hearing aids within that time period who replaced them with new devices before the end of 2018, which would decrease the population estimate. Additionally, there are people still wearing their hearing aids who acquired them more than 5 years ago, which would increase the population estimate. There are also people who purchased hearing aids in that time period who have died. Despite these additional uncertainties, we will use the estimate of 8.7 million people for the HD-HL group with hearing aids.

Fig. 2 shows the adult population segments assuming 8.7 million hearing aid wearers, 25.3 million in the HD-NHL population, 38.1 million in the total HL group, and 37.4 million in the total HD group. Population estimates of Segments E and B can be calculated to keep mathematical consistency with these defined constraints. This results in an estimate of population size in Segment E, or the HDNHL population who do not have hearing aids, to be 3.4 (37.4-25.3-8.7) million people, after which the NHD-HL group can be estimated to be 26 (38.1-8.7-3.4) million people. See Fig. 3 for the final population estimates. These two calculations are dependent on the assumptions of the population sizes for the other population segments and can therefore change dramatically if one or more of the other segment size estimates change.

One of the most problematic assumptions in the creation of the segment population in Fig. 3 was the size of the total HD population (the sum of Segments C, D, and E) because many of the population estimates for Segment $\mathrm{C}$ alone exceeded the population estimates for the sum of Segments C, D, and E, which cannot be valid. One could argue that a larger number should have been used for the sum of Segments C, D, and $E$ than 38.2 million. If an estimate of, say, 50 million were used, then the estimate for the population of Segment E would be 16 million instead of 3.4 million. The 3.4 million number 


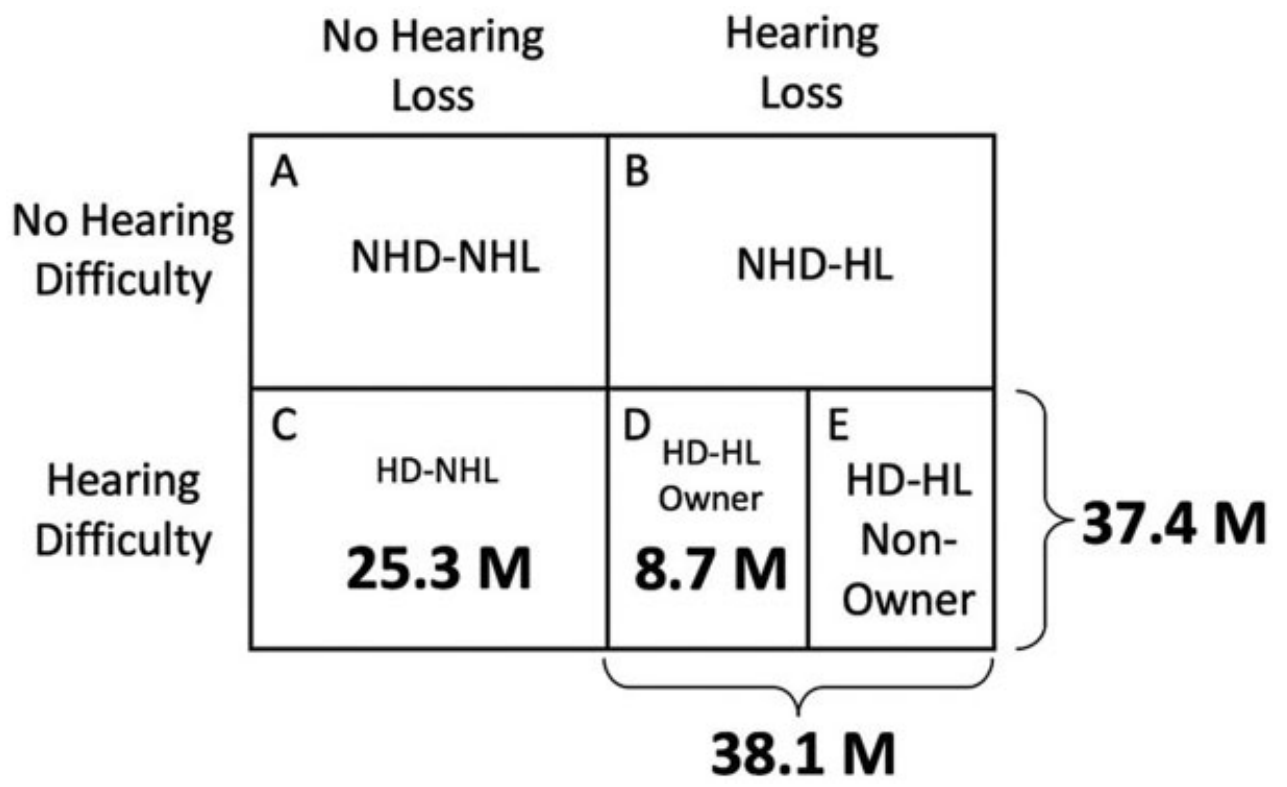

Figure 2 Estimated U.S. adult population numbers for those with self-reported hearing difficulty and no audiometric hearing loss (C), those who are hearing aid owners (D), the total population with audiometric hearing loss in both ears $(B+D+E)$, and the total population with self-reported hearing difficulty $(C+D+E)$. Numbers represent millions.

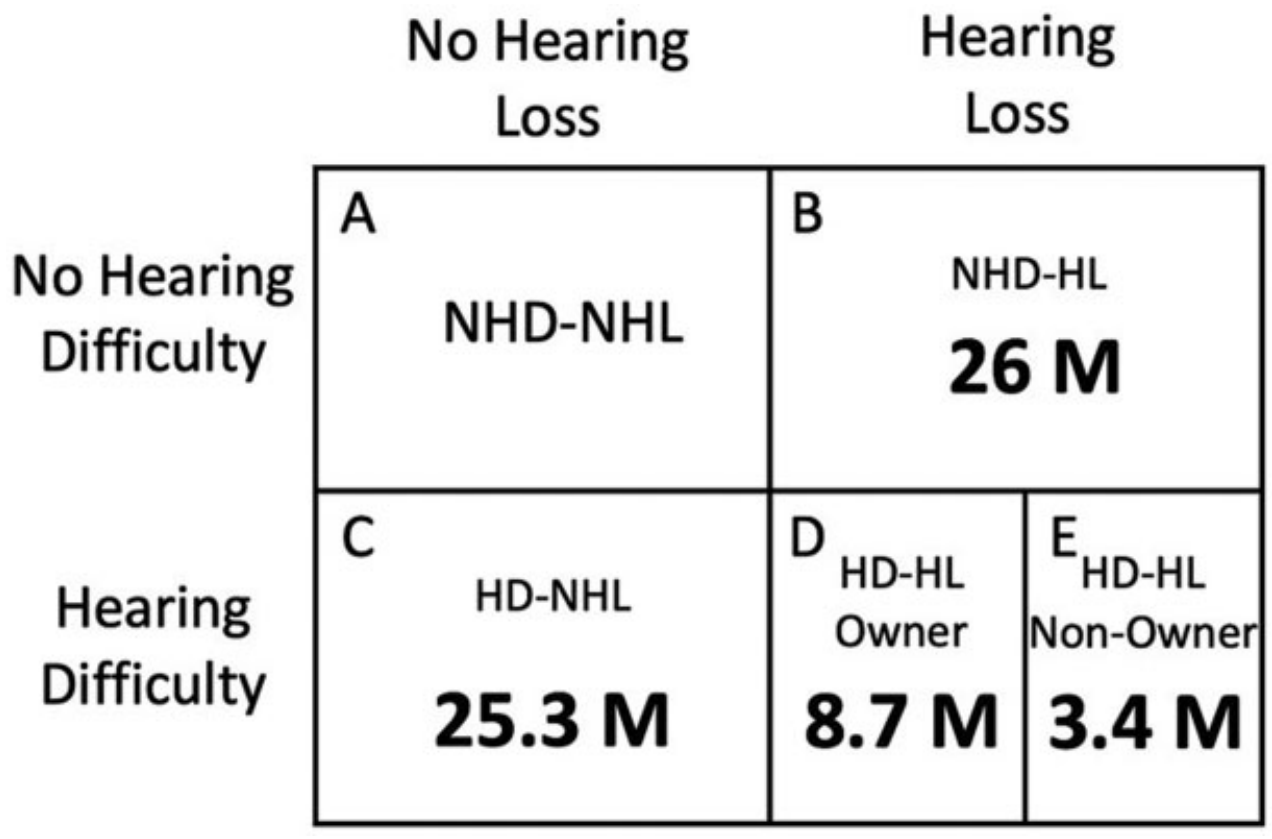

Figure 3 The estimated U.S. adult population numbers for different segments of those with auditory dysfunction. Segments B and E were calculated from the numbers given in Figure 2. Numbers represent millions. 
seems low considering that Kochkin ${ }^{44}$ estimated that there were 8.8 million people without hearing aids who had a similar hearing loss composite score as those with hearing aids. This is important because the total viable hearing aid market is assumed to be the sum of Segments $\mathrm{D}$ and $\mathrm{E}$, and the potential OTC market can be estimated to be at least the size of Segment E.

So, after all of this, what can be said about the potential market size for hearables and OTC hearing aids? The population for whom hearables may address an unmet need is the HD-NHL group, which has been estimated to be at least 25.3 million adults in the United States. This is a significant untapped market-much larger than the population of current hearing aid wearers. Organizations looking to provide solutions with hearables do not need to focus on current hearing aid wearers as their target market, since they appear to be happy with their hearing aids and $\mathrm{HCP}$ as will be discussed later, but focus on addressing the unique unmet needs of the HD-NHL group.

The potential market for OTC hearing aids is at least the population in Segment E, the HD-HL group without hearing aids. Possible customers also could include people in Segment D, the HD-HL group with hearing aids. Whether people in Segment D have a need for such a device remains to be seen and will be investigated in the next section. What is clear is that the people in Segment B, the NHD-HL group, are unlikely to be candidates for OTC devices primarily because they do not self-perceive as having a hearing problem and therefore OTC hearing aids will not address any need for people in this population. Using the numbers in Fig. 3, $72 \%$ of those who could benefit from a hearing aid have one, much larger than the 14 to $33 \%$ estimated in the NAS report or the 15 to $30 \%$ estimated in the PCAST report. Additionally, $68 \%$ of those with audiometric hearing loss have no self-perceived hearing difficulty, similar to the $66 \%$ number found for the percentage of Canadians aged 40 to 79 with moderate-to-profound high-frequency audiometric hearing loss who do not self-report as having hearing loss, ${ }^{45}$ albeit using a different criteria for audiometric hearing loss.

\section{MARKETRAK OVER-THE-COUNTER RESULTS}

With the creation of an OTC category of hearing aid looming, MarkeTrak 10 asked several questions related to the potential success of these devices to meet the unmet needs of the HD population.

The questions about OTC hearing aids were preceded with the following information:

- "In the near future, consumers with mild/ moderate hearing loss will have the option to purchase hearing aids 'OTC' (on their own, from a store, Web site, etc.) without the current requirement to be assessed by a hearing care professional first (which is required in all states). Note: Currently, personal sound amplifiers (that look like hearing aids) can be purchased directly without this requirement."

- "When purchasing "OTC," the cost of the hearing aid would be lower because there would be no hearing evaluation, counseling, fitting, or follow-up provided by a professional before, during, or after the sale."

MarkeTrak 10 queried 963 individuals who self-identified as having a hearing difficulty and who currently own a hearing aid. When asked if they would have purchased an OTC hearing aid instead of going to a professional if the option had been available to them, few said that they would have, with $88 \%$ responding that they either probably or definitely still would have purchased a hearing aid through an $\mathrm{HCP}$ (see Fig. 4). Fig. 5 shows the breakdown of responses by age and gender, with little difference across groups, although there was a slight tendency for the youngest age group to respond in the "not sure" category compared with the older groups. The respondents in this group come from Segment D, where high satisfaction with their current HCP may be one reason that they rated OTC hearing aid opportunities low. Because they do not perceive themselves as having an unmet need, they may not have perceived value in an OTC solution. Whether they might perceive OTC hearing aids as meeting their needs in the future when they look to replace their hearing aids remains to be seen. 


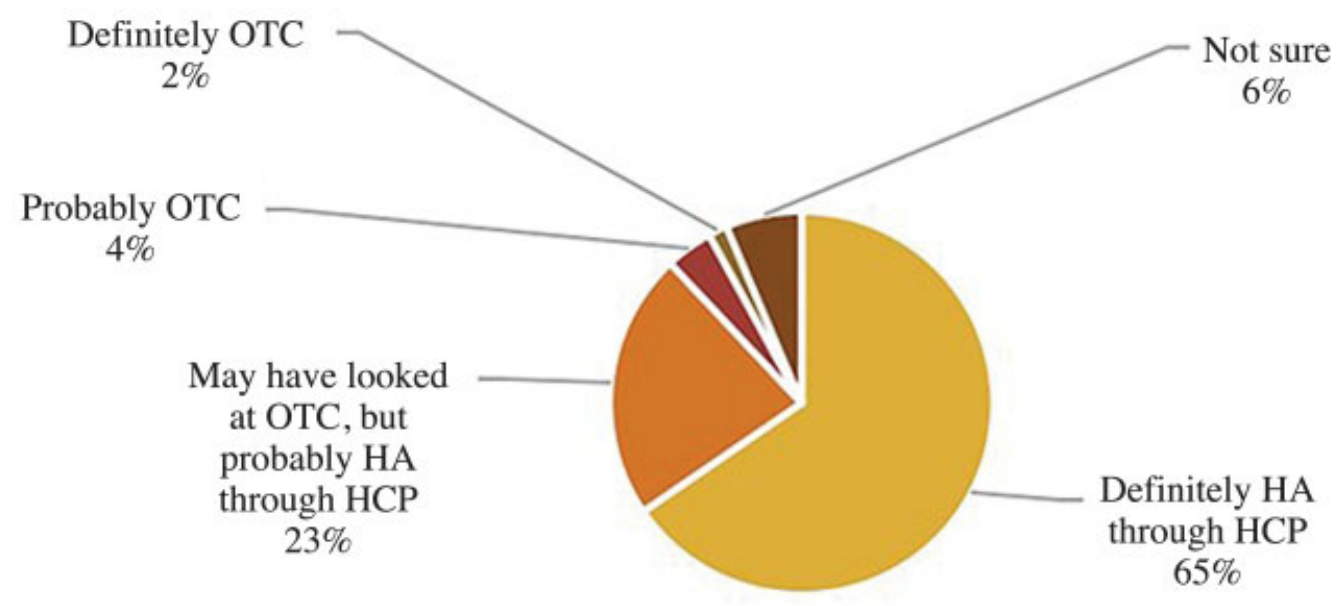

Figure 4 MarkeTrak 10 data showing responses from 963 hearing aid owners to: "If the option to purchase 'over the counter,' without a requirement to be assessed by a hearing care professional first, had been available when you purchased your hearing aids through a professional, how do you think you would have purchased?"

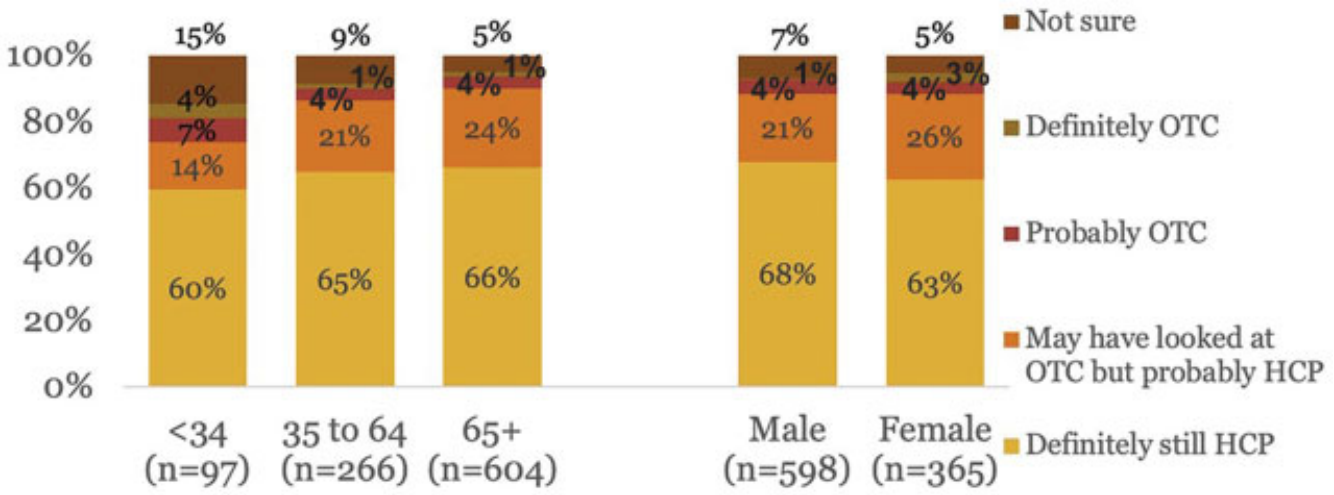

Figure 5 Data from Figure 4 separated by age and gender.

MarkeTrak 10 also queried 2,141 individuals who self-identified as having a hearing loss but do not own a hearing aid. The majority of this group said that if OTC hearing aids were available, they would still be likely to purchase a hearing aid through an HCP rather than purchase an OTC hearing aid, with only $22 \%$ saying that they probably or definitely would purchase an OTC hearing aid (see Fig. 6). Fig. 7 shows the breakdown of responses by age and gender, with little difference across groups.

To understand why people responded the way they did to the OTC hearing aid purchase likelihood question, MarkeTrak 10 also asked questions about their level of comfort doing hearing device-related tasks themselves and their attitudes toward HCPs.
When 3,113 respondents who had hearing difficulty were asked how comfortable they would be doing a variety of tasks without the help of an HCP, approximately one-third to one-half of the people responded that they were not very comfortable or not comfortable at all doing the tasks on their own. These tasks were assessing their hearing loss, selecting an appropriate hearing aid, getting started with the hearing aids, using features to adjust their hearing aids, learning/maintaining their hearing aids, and troubleshooting (see Fig. 8). Interestingly, people were most comfortable with cleaning and maintaining their hearing aids, which may be due to a lack of awareness of what is required to maintain a hearing aid. Since the majority of respondents to these questions 


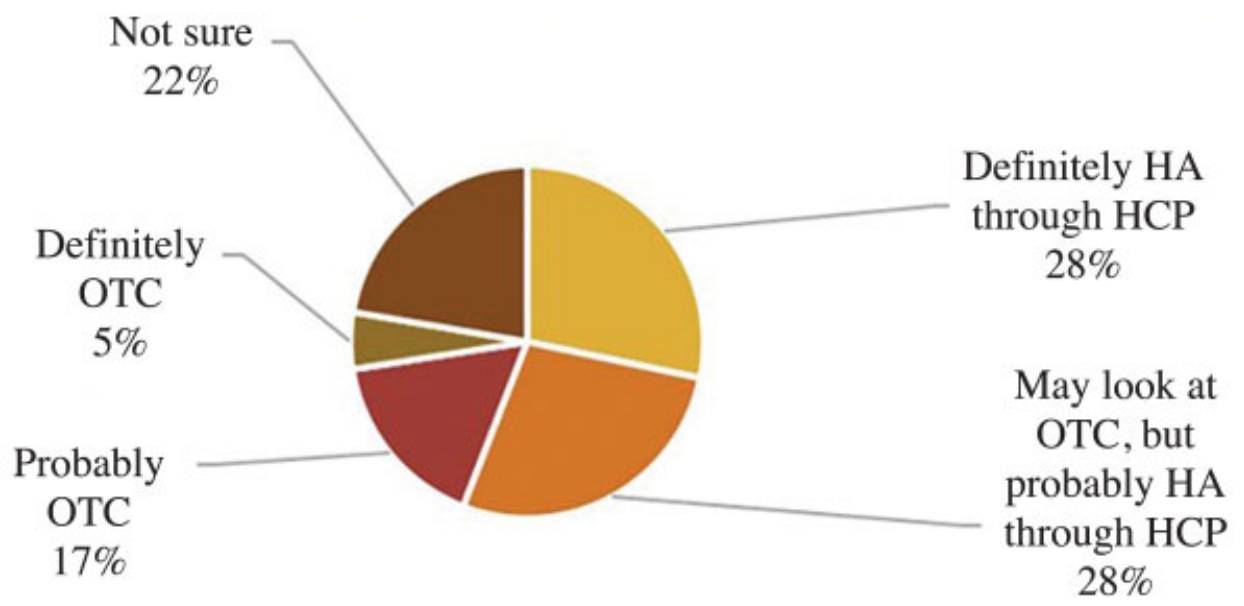

Figure 6 MarkeTrak 10 data showing responses from 2,141 current hearing aid nonowners to: "Assume you decided to get hearing aids and the option to purchase 'over the counter,' without the current requirement to be assessed by a hearing care professional first, was available. How do you think you would purchase?"

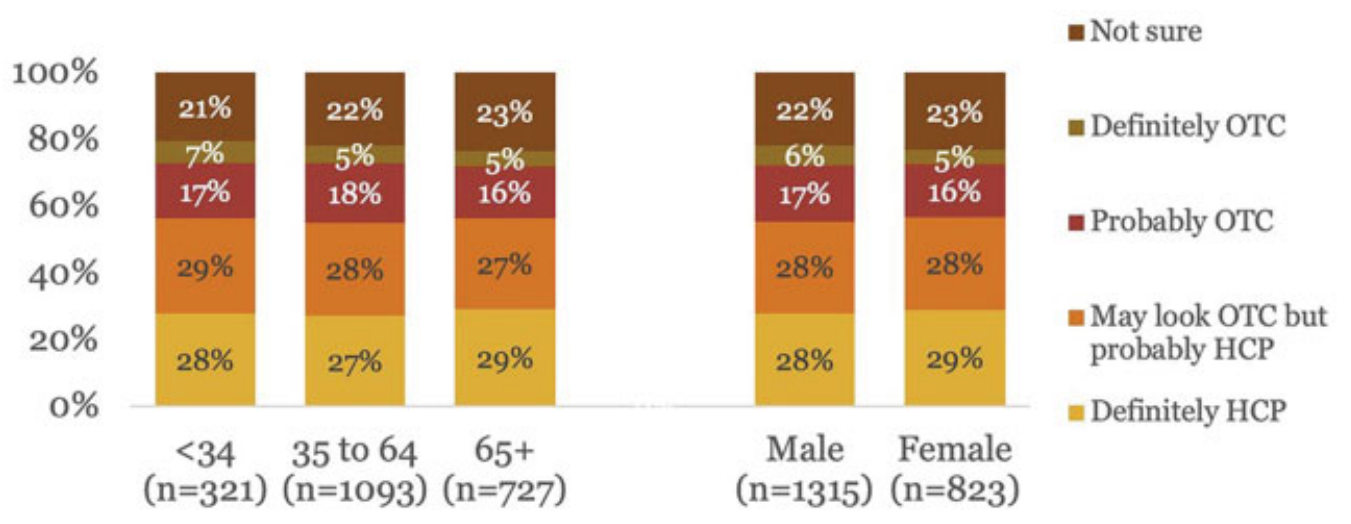

Figure 7 Data from Figure 6 separated by age and gender.

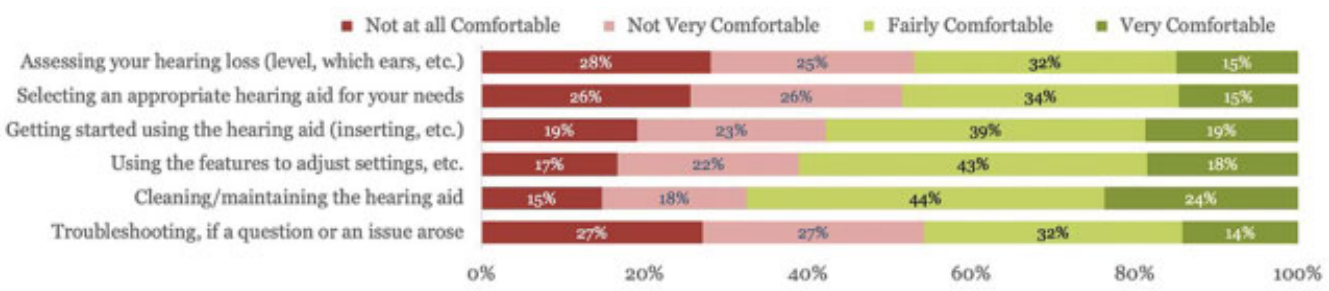

Figure 8 Responses from 3,113 people who self-report as having hearing difficulty to "How comfortable are you or would you be doing the following on your own, without the assistance of a hearing care professional?"

were hearing aid nonowners, they were likely unaware of what is necessary to succeed in doing any of these tasks. Fig. 9 shows the breakdown of responses by age and gender, showing that the level of comfort with these tasks was highest for those younger than 65 years and males.
MarkeTrak 10 asked current hearing aid owners how much their HCP helped with the process of selecting, getting used to, and using their hearing aids. Sixty-nine percent of the respondents said that they received a great deal of help, while another $21 \%$ said that they 


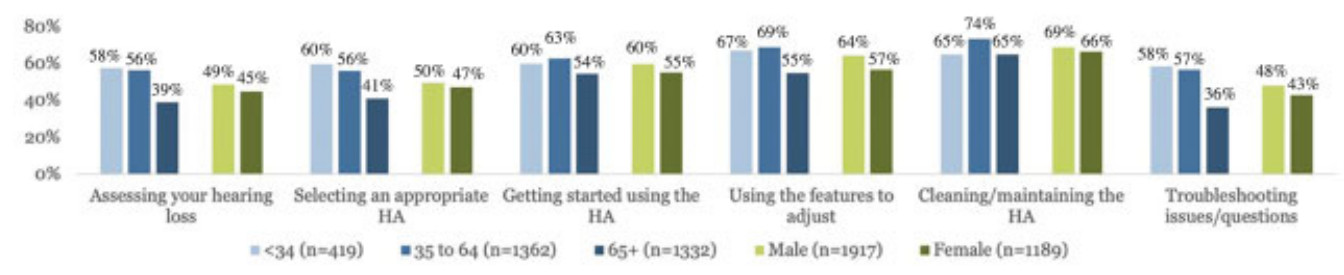

Figure 9 Data from Figure 8 broken down by age and gender.

received a moderate amount of help (see Fig. 10). When the results are broken down by age and gender, appreciation for the HCP increases with age, but there is no difference in gender (see Fig. 11).

A related question was given to people with hearing difficulty who had obtained hearing devices through means other than an HCP. These devices could be noncompliant hearing aids obtained through the mail or could be devices intended to help with hearing but not treat hearing loss. This group of people is labeled PSAP (personal sound amplification product) owners. Of the 193 PSAP owners polled, $66 \%$ said that they feel they would have benefited from an HCP in selecting, getting used to, and using their PSAPs, with only $3 \%$ saying that they would not have benefited at all (see Fig. 12). These data suggest that even if people do not have experience with
$\mathrm{HCPs}$, they realize that the $\mathrm{HCP}$ can make a difference in hearing help.

\section{MarkeTrak Over-the-Counter Results Discussion}

There are likely several reasons why the MarkeTrak 10 data showed that the majority of respondents stated a preference to see an $\mathrm{HCP}$ for their hearing health rather than select an OTC solution. Of primary concern could be their attitude toward the severity of their hearing loss and the need to see a health care professional about a health issue. The respondents who were hearing aid owners have experience with their HCP and their response could be based on their perception of the capabilities and skills that the HCP brought to helping them with their hearing. The group who were not owners of hearing aids has less or no

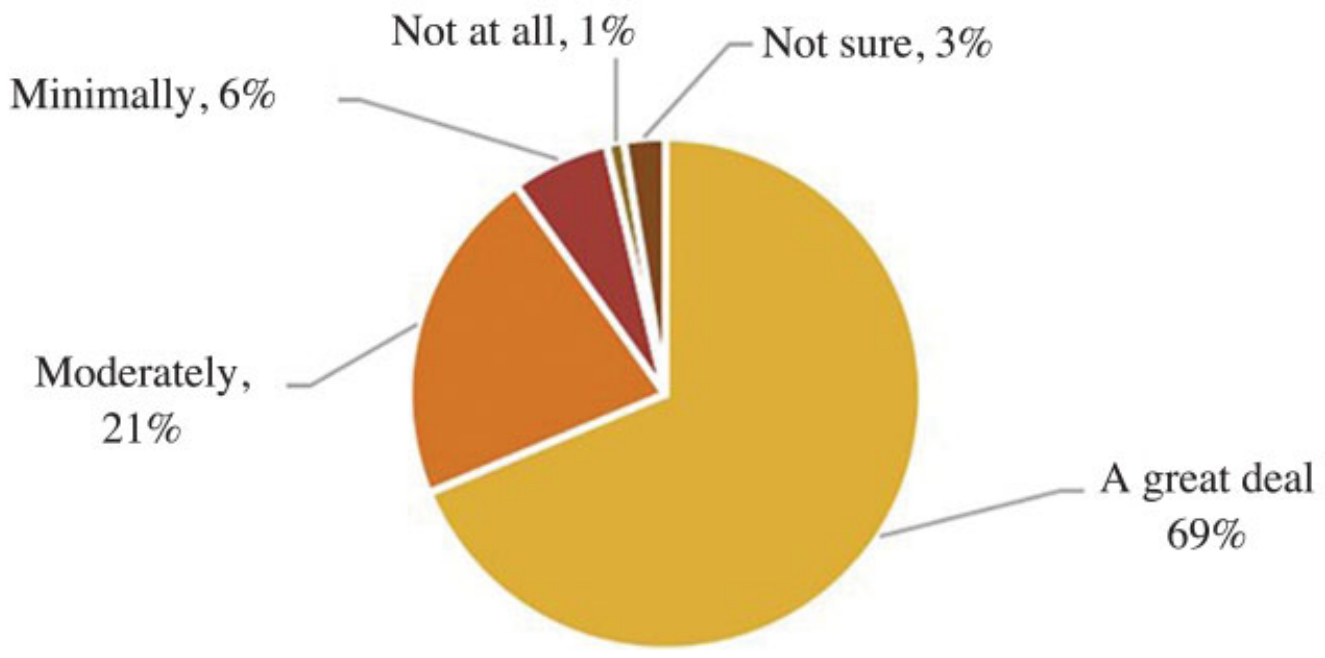

Figure 10 MarkeTrak 10 data showing responses from 960 current hearing aid owners to: "Given your experience working with a hearing care professional during the process of selecting, getting used to, and using your hearing aid(s), how much, if at all, did they help you along the way?" 


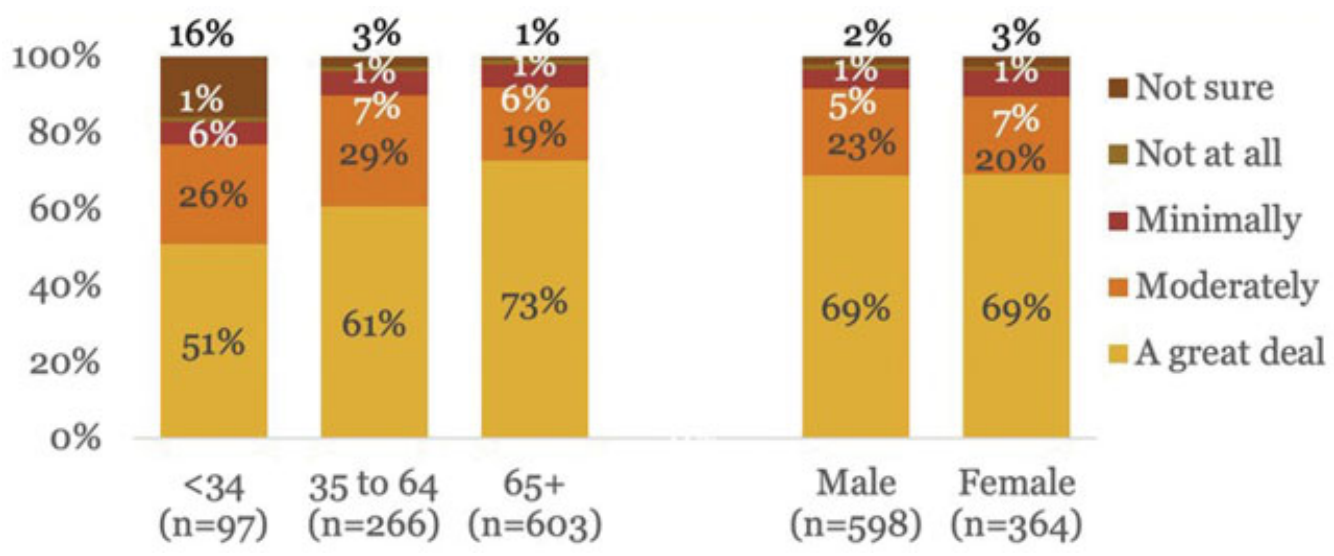

Figure 11 Data from Figure 10 separated by age and gender.

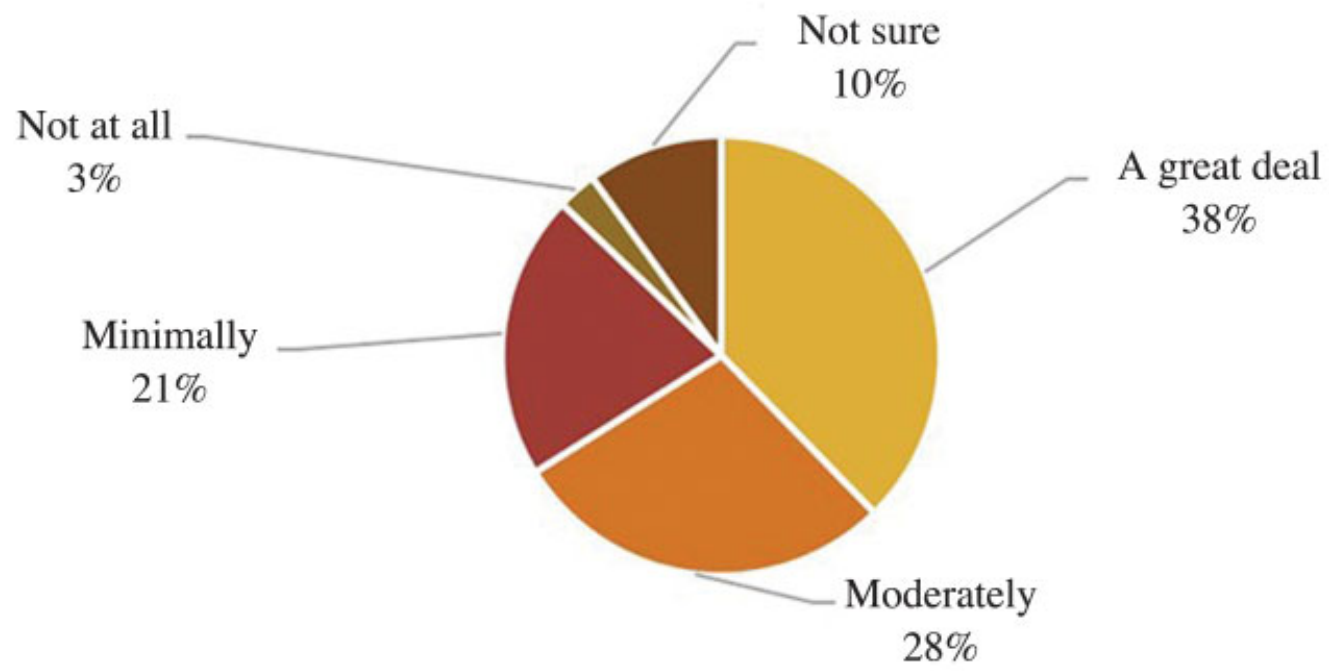

Figure 12 MarkeTrak 10 data showing responses from 193 current PSAP owners to: "Given your experience selecting, getting used to, and using your hearing device or personal amplifier, that you got directly, on your own, how much, if at all, do you feel you would have benefited from having a hearing care professional help you along the way?"

experience with HCPs, but, regardless, they might still have an expectation of the benefit that an HCP would bring. Hearing loss is a health care issue and it would not be surprising that many people generally are more comfortable seeing a health care professional for healthrelated issues. The fact that they self-report having hearing difficulty yet are not hearing aid owners does not necessarily reflect an unwillingness to see an HCP but could be because of many of the other reasons for not getting hearing aids discussed earlier, such as stigma or lack of social support.
On the other hand, the fact that PSAP owners reported that they would have benefited from an HCP does not necessarily mean that they are open to seeing an HCP for hearing help; many of us likely believe that we would benefit from some professional help in things that we do ourselves (fitness routines, setting up home entertainment systems) even though we do not actually seek professional help for those activities. What the data from Figs. 10 and 12 show is that lack of perceived benefit from an $\mathrm{HCP}$ is unlikely to be a reason that most people with hearing difficulty do not have hearing aids. 
The MarkeTrak 10 respondents with hearing difficulty but no hearing aids consist of people from the HD-NHL and HD-HL groups (Segments $\mathrm{C}$ and $\mathrm{E}$ from Fig. 1, respectively), and each of these segments have unmet needs that traditional HCP-provided hearing aids may not be solving.

The concept of an OTC hearing aid was not fully detailed in MarkeTrak 10 before people were asked questions about OTC hearing aids. The information presented was intended to be a very high-level category concept gauge-not as an assessment of a specific marketing or sales pitch (since the approach will vary dramatically as actual products and brands are more fully developed and marketed). The respondents were informed that OTC hearing aids did not involve an HCP and were lower in cost but were left on their own to imagine such things as what OTC hearing aids look like, what the process would be to fit them, and whether a complicated hearing test would be needed for use. It is possible that when presented with an actual OTC hearing aid and tangible information about it - with possibly a trusted brand on the device, compelling marketing messages about benefit and ease of fit, some sort of "FDA-approved" messaging on the packaging, and an actual price that can be assessed for valueintent to purchase attitudes shown in Figs. 4 and 6 might change. Comfort with doing hearing device-related tasks shown in Fig. 8 also might improve with appropriate marketing, packaging, and training materials provided. ${ }^{46}$

With respect to the pending OTC hearing aid market, these results tell us that the majority of the potential customers for OTC hearing aids currently view HCPs favorably and are not going to seek self-fitting hearing aids solely because they believe HCPs are unnecessary. The majority of potential customers also have concerns about their ability to manage the various aspects of getting, fitting, and using OTC hearing aids, which will be a barrier that needs to be overcome by those selling OTC hearing aids. Other potential barriers also exist, as will now be discussed.

\section{OVER-THE-COUNTER CHALLENGES}

The creation of an OTC hearing aid category will address one of the major challenges that has been faced by traditional consumer electronics companies considering entering the hearing aid market, which has been the unique distribution requirements of selling to a variety of $\mathrm{HCPs}$, from large chains to individual practices, with different regulatory requirements in different states. This unique distribution channel requires sales, marketing, and training forces different from those of typical consumer electronics companies. Competing successfully in the hearing aid market, then, has been a challenge for many new entrants.

Hearing aids also have unique requirements to be successful that can be much more difficult than typical consumer audio products. MarkeTrak 10 found that hearing aid owners wear their hearing aids on average 9.9 hours on days that they were worn. This duration of continuous wear requires extremely low-power electronics to enable the devices to last all day without recharging them (or several days before changing batteries if not rechargeable). This also gives a high priority to comfort, which can be challenging for a device worn on or in the ear for several continuous hours each day. Acoustic effects like occlusion, feedback, and comb filtering also provide unique challenges to the physical design of the product. For example, reducing occlusion typically demands a loose or open fitting, while reducing feedback requires a tight or closed fitting. The presence of wax, sweat, humidity, hair spray, and other materials significantly affect the reliability of hearing aids such that their repair and remake rates are much higher than traditional audio consumer electronics. ${ }^{38}$ Hearing aid companies have spent decades solving these problems. While the promotion of new hearing aid products typically focuses on innovative features such as improved directional microphones, new signal processing enhancements, and wireless capabilities, significant effort goes on in quality engineering and manufacturing to ensure that the quality of the product from a comfort, ease of use, and reliability perspective is high. These will be some of the challenges facing new entrants to the OTC hearing aid marketplace, in a field that typically has high return, repair, and remake rates and high customer support requirements.

While the aforementioned issues will likely lead to the presence of some OTC hearing aids 
with unsatisfactory quality and performance, these challenges are not insurmountable and eventually there will likely be OTC hearing aids that have equivalent performance and quality as HCP-fit hearing aids. The bigger unknown and possibly more significant challenge will be issues with the capability of the OTC hearing aid wearer and the fitting of the device to the user's loss.

One open question is what type of person will be successful with a self-fit hearing aid. In a study of 60 subjects' ability to successfully fit themselves with a hearing aid designed for selffitting that would be a candidate for OTC, Convery et $\mathrm{al}^{47}$ found that only $25 \%$ of the subjects were successful without the help of a trained assistant; $43 \%$ of the subjects were successful if they received assistance from a trained clinical assistant, while 32\% never achieved success fitting a hearing aid themselves. Factors that predicted success included cognitive ability, locus of control, problem-solving skills, and self-efficacy. Clearly, these results are dependent on the specifics of the design, ease of use, and training materials for the self-fitting hearing aid under test, which will vary with different products. What is clear is that technology alone will not determine whether someone can be successful with an OTC hearing aid.

Another open question is how successful OTC hearing aid users will be without the assistance of an HCP. HCPs spend many hours with hearing aid wearers to make them successful with their devices, providing training, counseling, and encouragement to overcome some of the challenges with hearing aid use and becoming successful hearing aid wearers. While providing good quality technology, improved audibility and speech understanding are important for hearing aid success, there are other factors that influence success with hearing aids that the HCP can influence, such as providing positive attitudes to hearing aids and help with perceived self-efficacy in using hearing aids. ${ }^{48,49}$ Several studies have found that success and satisfaction with hearing aids were correlated with the perceived care from and satisfaction with their HCP during the fitting and counseling process. ${ }^{50-53}$ These results indicate that, for those who have received $\mathrm{HCP}$-fit hearing aids, the HCP plays an important role in getting the user to be successful and satisfied with their hearing aids. Lack of access to an HCP may affect success and satisfaction with OTC hearing aids, consistent with findings that those dissatisfied with self-fit hearing aids became more satisfied and successful with subsequent help from an HCP. ${ }^{54,55}$

\section{SELF-FITTING TECHNOLOGY}

Another challenge will be the fitting of the OTC hearing aids to the hearing loss of the user. In the traditional hearing aid world, significant effort is placed in fitting the gain and compression ratio to the audiogram of the client and then fine-tuning those features based on client feedback. OTC hearing aids could come with fitting software or apps that allow people to measure their own audiograms from which gain and compression can be prescribed, or the user could individualize the gain and compression in a completely different way that does not require a hearing test.

Self-measurement of hearing thresholds is a feasible approach if the usability of the interface is well designed. ${ }^{56-58}$ In a quiet room with proper interface controls, a person can reasonably adjust the sound level of a tone until it is near the threshold of audibility. For the purposes of an OTC hearing aid used by someone with mild-moderate hearing loss, precisely measured thresholds are unlikely to be necessary. Once hearing thresholds are measured with, say, a smartphone app, a fitting prescription such as NAL-NL2 or DSL-I/O could be used in the app to program the gain and compression of the hearing aids through a wireless connection. Thus, the self-measurement of hearing thresholds and application of a fitting prescription could be one way to personalize an OTC hearing aid.

Another method could be to forgo measuring the consumer's hearing ability and to simply allow them to adjust the hearing aid features until some preferred setting is selected. This could be accomplished through selecting one of several presets offered or the provision of an interface that allows the user to adjust the gain and compression parameters themselves. The latter has been proven to be successful with several different approaches. ${ }^{59,60}$ 
Other approaches to user-selected settings exist and new ones will be developed, suggesting that users can get to a satisfactory setting for their hearing aids without the intervention of a professional if the self-tuning software is well designed and the user capable. A restriction of OTC hearing aids to mild-moderate perceived losses, as intended with the OTC legislation, will restrict the range of gain and compression ratios that these methods will need to make available for selection.

\section{CONCLUSION}

The introduction of new hearing health product categories will allow for an expansion of the viable market for hearing care by addressing the unmet needs of different consumer segments. Those with self-reported hearing difficulty but no audiometric hearing loss are potential consumers for hearable devices. OTC hearing aids will open the market to those with audiometric hearing loss and a selfperceived need for hearing help who have, for whatever reason, rejected $\mathrm{HCP}$-fit hearing aids as a solution. Those with an audiometric hearing loss but no self-perceived difficulty, which appears to be a large segment of the total population with an audiometric hearing loss, should not be considered candidates for hearing aids or other hearing solutions/delivery methods described in this article because they do not have a self-perceived need or are not ready, willing, or able to admit it. The viable hearing aid market is thus smaller than previously estimated.

Whether OTC hearing aids are able to overcome barriers to acceptance of hearing solutions beyond accessibility and affordability, such as stigma and perceived self-efficacy, remains to be seen. MarkeTrak data show that there is concern among people with hearing difficulty over whether they can manage some of the steps necessary to select and fit a hearing aid without the assistance of an HCP. Data also suggest that HCPs play a significant role in making a hearing aid wearer a successful and satisfied user. Whether OTC devices will provide solutions that overcome some of the barriers to being a successful user also remains to be seen.
CONFLICT OF INTEREST

There are no conflicts of interest.

\section{REFERENCES}

1. Govindarajan V, Desai J. Innovation isn't just about new products. Harvard Business Review blog. 2013. Available at: https://hbr.org/2013/09/innovation-isnt-just-about-new-products. Accessed August 28, 2019

2. Sarampalis A, Kalluri S, Edwards B, Hafter E. Objective measures of listening effort: effects of background noise and noise reduction. J Speech Lang Hear Res 2009;52(05):1230-1240

3. Desjardins JL, Doherty KA. The effect of hearing aid noise reduction on listening effort in hearingimpaired adults. Ear Hear 2014;35(06):600-610

4. Hornsby BW. The effects of hearing aid use on listening effort and mental fatigue associated with sustained speech processing demands. Ear Hear 2013;34(05):523-534

5. Weinstein BE, Sirow LW, Moser S. Relating hearing aid use to social and emotional loneliness in older adults. Am J Audiol 2016;25(01):54-61

6. Edwards B. The future of hearing aid technology. Trends Amplif 2007;11(01):31-45

7. Picou EM, Ricketts TA. An evaluation of hearing aid beamforming microphone arrays in a noisy laboratory setting. J Am Acad Audiol 2019;30 (02):131-144

8. Visagie A, Swanepoel W, Eikelboom RH. Accuracy of remote hearing assessment in a rural community. Telemed J E Health 2015;21(11):930-937

9. Convery E, Keidser G, McLelland M, Groth J. A smartphone app to facilitate remote patient-provider communication in hearing health care: usability and effect on hearing aid outcomes. Telemed J E Health 2019. Doi: 10.1089/tmj.2019.0109 [Epub ahead of print]

10. Kochkin S. MarkeTrak VIII: utilization of PSAPs and direct-mail hearing aids by people with hearing impairment. Hearing Rev 2010;16(06):12-16

11. Strom KE. BlameySaunders and the "Blended Model" in hearing aid dispensing. Hearing review. 2019. Available at: http://www.hearingreview.com/ 2019/04/blog-blameysaunders-blended-modelhearing-aid-dispensing/. Accessed August 28, 2019

12. Hodsden S. FDA clears first at-home hearing test, pushes for hearing aid innovation. Available at: https://www.meddeviceonline.com/doc/fda-clearsfirst-at-home-hearing-test-pushes-for-hearingaid-innovation-0001. Published 2016. Accessed August 28, 2019

13. Sandström J, Swanepoel W, Carel Myburgh H, Laurent C. Smartphone threshold audiometry in underserved primary health-care contexts. Int J Audiol 2016;55(04):232-238 
14. Hunn N. The market for hearable devices 20162020. Available at: http://www.nickhunn.com/wpcontent/uploads/downloads/2016/11/The-Market-for-Hearable-Devices-2016-2020.pdf. Published 2016. Accessed August 28, 2019

15. President's Council of Advisors on Science and Technology. Aging America \& Hearing Loss: Imperative of Improved Hearing Technologies. Washington, DC: Executive Office of the President of the United States; 2015

16. National Academies of Sciences, Engineering, and Medicine. Hearing health care for adults: priorities for improving access and affordability. Available at: http://www.nationalacademies.org/hmd/Reports/ 2016/Hearing-Health-Care-for-Adults.aspx. Accessed August 28, 2019

17. Warren E, Grassley C. Over-the-counter hearing aids: the path forward. JAMA Intern Med 2017; 177(05):609-610

18. Jerger J. Why do people without hearing loss have hearing complaints? J Am Acad Audiol 2011;22 (08):490

19. Davis A, Smith P, Ferguson M, Stephens D, Gianopoulos I. Acceptability, benefit and costs of early screening for hearing disability: a study of potential screening tests and models. Health Technol Assess 2007;11(42):1-294

20. Wingfield A, Tun PA, McCoy SL. Hearing loss in older adulthood: what it is and how it interacts with cognitive performance. Curr Dir Psychol Sci 2005; 14(03):144-148

21. Tahden MAS, Gieseler A, Meis M, Wagener KC, Colonius $\mathrm{H}$. What keeps older adults with hearing impairment from adopting hearing aids? Trends Hear 2018;22:2331216518809737

22. Edwards B. What outsiders tell us about the hearing industry. Hearing Rev 2006;13(03):88-92

23. Spankovich C, Gonzalez VB, Su D, Bishop CE. Self reported hearing difficulty, tinnitus, and normal audiometric thresholds, the National Health and Nutrition Examination Survey 1999-2002. Hear Res 2017. Doi: 10.1016/j.heares.2017.12.001 [Epub ahead of print]

24. Beck DL, Danhauer JL, Abrams HB, et al. Audiologic considerations for people with normal hearing sensitivity yet hearing difficulty and/or speechin-noise problems. Hearing Rev 2018;25(10): 28-38

25. Abrams HB, Kihm J. An introduction to MarkeTrak IX: a new baseline for the hearing aid market. Hearing Rev 2015;22(06):16

26. Kochkin S. MarkeTrak VIII: the key influencing factors in hearing aid purchase intent. Hearing Rev 2012;19(03):12-25

27. Hickson L, Meyer C. Improving uptake and outcomes of hearing aid fitting for older adults: what are the barriers and facilitators? Int J Audiol 2014; 53(Suppl 1):S1-S2
28. Wallhagen MI. The stigma of hearing loss. Gerontologist 2010;50(01):66-75

29. United States Census Bureau. Age and Sex Composition in the United States: 2018. Available at: https://www.census.gov/data/tables/2018/demo/ age-and-sex/2018-age-sex-composition.html. Accessed Aug 28, 2019

30. Blackwell DL, Lucas JW, Clark TC. Summary health statistics for U.S. adults: National Health Interview Survey, 2012. 2012;10. Available at: http://www.cdc.gov/nchs/data/series/sr_10/ sr10_260.pdf. Accessed August 28, 2019

31. Goman AM, Lin FR. Prevalence of hearing loss by severity in the United States. Am J Public Health 2016;106(10):1820-1822

32. Gates GA, Cooper JC Jr, Kannel WB, Miller NJ. Hearing in the elderly: the Framingham cohort, 1983-1985. Part I. Basic audiometric test results. Ear Hear 1990;11(04):247-256

33. Garstecki D. Self-perceived hearing difficulty in aging adults with acquired hearing loss. J Acad Rehabilitative Audiol 1987;20:49-60

34. Taylor B, Manchaiah V, Clutterbuck S. Using the personal assessment of communication abilities (PACA) tool. Hearing Rev 2016;23(03):20

35. Tremblay KL, Pinto A, Fischer ME, et al. Selfreported hearing difficulties among adults with normal audiograms: the Beaver Dam Offspring Study. Ear Hear 2015;36(06):e290-e299

36. Chien W, Lin FR. Prevalence of hearing aid use among older adults in the United States. Arch Intern Med 2012;172(03):292-293

37. Popelka MM, Cruickshanks KJ, Wiley TL, Tweed TS, Klein BE, Klein R. Low prevalence of hearing aid use among older adults with hearing loss: the Epidemiology of Hearing Loss Study. J Am Geriatr Soc 1998;46(09):1075-1078

38. Strom KE. Hearing aid sales increase by $4.8 \%$ in 2014; RICs continue market domination. Hearing Rev 2015;22(03):6

39. Strom KE. The invisible hand. Hearing Rev 2016; 23(02):6

40. Strom KE. Hearing sales up $8.7 \%$ in 2016 . Hearing Rev 2017;24(02):6

41. Strom KE. Hearing aid sales increase by $3.4 \%$ in 2017. Hearing Rev 2018;25(02):6

42. Strom KE. Hearing aid sales increase by $5.3 \%$ in 2018; fall just short of 4-million. Hearing Rev 2019;26(02):6

43. Kochkin S. MarkeTrak VIII: consumer satisfaction with hearing aids is slowly increasing. Hear J 2010; 63(01):19-32

44. Kochkin S. MarkeTrak VII - obstacles to adult non-adoption of hearing aids. Hear J 2007;60(04): 24-50

45. Ramage-Morin PL, Banks R, Pineault D, Atrach $\mathrm{M}$. Unperceived hearing loss among Canadians aged 40 to 79. Health Rep 2019;30(08):11-20 
46. Ferguson M, Brandreth M, Brassington W, Leighton $\mathrm{P}$, Wharrad $\mathrm{H}$. A randomized controlled trial to evaluate the benefits of a multimedia educational program for first-time hearing aid users. Ear Hear 2016;37(02):123-136

47. Convery E, Keidser G, Hickson L, Meyer C. Factors associated with successful setup of a selffitting hearing aid and the need for personalized support. Ear Hear 2019;40(04):794-804

48. Hickson L, Meyer C, Lovelock K, Lampert M, Khan A. Factors associated with success with hearing aids in older adults. Int J Audiol 2014;53 (Suppl 1):S18-S27

49. Saunders GH, Lewis MS, Forsline A. Expectations, prefitting counseling, and hearing aid outcome. J Am Acad Audiol 2009;20(05):320-334

50. Kochkin S, Beck DL, Christensen LA, et al. MarkeTrak VIII: the impact of the hearing healthcare professional on hearing aid user success. Hearing Rev 2010;17(04):12-34

51. Uriarte M, Denzin L, Dunstan A, Sellars J, Hickson L. Measuring hearing aid outcomes using the Satisfaction with Amplification in Daily Life (SADL) questionnaire: Australian data. J Am Acad Audiol 2005;16(06):383-402

52. Arlinger S, Nordqvist P, Öberg M. International outcome inventory for hearing aids: data from a large Swedish Quality Register database. Am J Audiol 2017;26(3S):443-450

53. Dillon H, Seeto M, Beechey T, Hickson L. Are good outcomes driven by good devices, good clini- cians, or good clients? 34th World Congress of Audiology; 2018; Cape Town, Republic of South Africa

54. Humes LE, Kinney DL, Main AK, Rogers SE. A follow-up clinical trial evaluating the consumerdecides service delivery model. Am J Audiol 2019; 28(01):69-84

55. Humes LE, Rogers SE, Quigley TM, Main AK, Kinney DL, Herring C. The effects of service-delivery model and purchase price on hearing-aid outcomes in older adults: a randomized double-blind placebocontrolled clinical trial. Am J Audiol 2017;26(01): 53-79

56. Mahomed F, Swanepoel W, Eikelboom RH, Soer M. Validity of automated threshold audiometry: a systematic review and meta-analysis. Ear Hear 2013;34(06):745-752

57. van Tonder J, Swanepoel W, Mahomed-Asmail F, Myburgh H, Eikelboom RH. Automated smartphone threshold audiometry: validity and time efficiency. J Am Acad Audiol 2017;28(03):200-208

58. Edwards B. Understanding new and emerging categories of hearing devices. ENT Audiol News 2019;28(05):51-52

59. Van Tasell DJ, Sabin A, Franck K. User selfadjustment of a simulated hearing aid using a mobile device. International Hearing Aid Research Conference; August, 2014; Lake Tahoe, CA

60. Valentine S, Dundas JA, Fitz K. Evidence for the use of a new patient-centered fitting tool. Hearing Rev 2011;18(04):28-34 